\title{
Sewer system optimization in housing and communal services
}

\author{
Elena Smirnova ${ }^{1, *}$, Yuliya Larionova ${ }^{2}$, and Arkadij Larionov ${ }^{2}$ \\ ${ }^{1}$ Saint Petersburg State University of Architecture and Civil Engineering, 4 Vtoraja \\ Krasnoarmejskaja, St. Petersburg, 190005, Russia \\ ${ }^{2}$ Moscow State University of Civil Engineering, 26 Yaroslavskoye shosse, Moscow, 129337, Russia
}

\begin{abstract}
The purpose of the article is to present the design decisions used in the construction of the extended main trunk sewer of the North in St Petersburg. One of its key elements is the siphon, a unique structure in engineering practice for optimal and safe water disposal system. Its special feature is in the arrangement of connections in the pits of the trunk sewer header portion. For the purpose of investigation it had to describe the general situation relative to sewerage network in the city. Following this, a precondition, which determined the structure design as the optimum for movement of effluent, is presented. Further, author concludes that the new pit structures using composite materials made it possible to complete construction of the trunk sewer on schedule and by means of it to move to purification works practically all of the city's effluents $(98,4 \%)$ and realize the goal of steady economic development. Then author shows that it is necessary source control techniques be designed to counter increased discharge of water. It should to provide in the buildings power saving technologies, the hot water recirculation systems, modernize the existing hot water supply facilities, and to install low-cost highly efficient small heat exchangers instead of obsolete locally based boilers and just only of increasing the norms, coefficients and tariffs. Hence it appears that the multi-objective sewer system optimization provides more rational and practical solutions to avoid sewer overflows, reduce risks to public health and to protect the environment from water pollution.
\end{abstract}

\section{Introduction}

Experience the world over shows that sewer construction and renewal is an expensive endeavor. In 2007 approximately J32 million were spent in Kolkata for the reconstruction of three trunk sewers - about $12 \mathrm{~km}$. The same year the separation of sewer systems in London was estimated at approximately J12-20bn [1]. In addition, expenditures for the construction of the Thames Tideway greatly escalated over just a few years: from J1.7bn in 2004 (including Lee Tunnel and sewage treatment works (STW)) to J3.6bn in 2012 for the shorter Thames Tunnel as far as Abbey Mills, plus some J1bn for the Lee Tunnel and

${ }^{*}$ Corresponding author: esmirnovae@ yandex.ru 
upgrade of works at Beckton [2]. In 2012, the construction of the project was already estimated at J4.2bn [3]. According to Brotchie et al. [4], the initial funding application in Melbourne included only simple estimates of costs which were obtained from town officials (slope, depth to bedrock, and nearness to existing facilities). But significant factors like the capacities of pipes and treatment plants and lowered unit costs with greater quantities of service (that is, economies of scale) were often ignored. A mathematical model for estimating the construction costs of sanitary sewers was developed by Earle and Farrell. Their model is useful in comparing design approaches, including gravity and pressure alternatives (for example, trench depth and lot width have a much greater influence on construction cost than manhole spacing). All estimates are calculated on a permile-of-sewer basis [5]. Application of the model has shown that, in many instances, lowpressure sewer systems offer a significant economic advantage in reduced capital costs versus gravity sewers [6]. On the other hand, many engineers and operating personnel have been, and some still are, unwilling to adopt LPS systems because they have concern that operating and maintenance requirements will be excessive. But if a system is properly designed and constructed, the actual operating costs are far lower and the maintenance much less frequent than would be expected based on conventional manner [7].

A study by Shukla and Tare estimates the per capita expenditure on sewer systems. Results indicate that the footprint for sewage treatment is approximately $0.1 \mathrm{~m}^{2}$ per person, which is one tenth of the size of a toilet. The higher expenditures correspond to towns with very low population density, and the lower values correspond to very high population densities [8]. Since 1985, in India, more than 70 sewage treatment plants have been constructed. However, the level of performance of these plants with regard to effluent quality, energy consumption, process stability, resource recovery, capital and O\&M costs, etc., has varied considerably. It is advisable that sewage is treated to recyclable water quality and used for various purposes, including recharging local water bodies such as lakes, ponds, etc. [9-10].

According to Dodane et al. (2012), in Dakar a financial comparison of a parallel sewer based (SB) system with activated sludge, and a fecal sludge management (FSM) system with onsite septic tanks, collection and transport (C\&T) trucks, and drying beds shows that SB is 40 times more expensive to implement for the utility than FSM. The results of their study illustrate that in low-income countries, vast improvements in sanitation can be affordable when employing FSM, whereas SB systems are prohibitively expensive [11]. However, in high-income countries (e.g. Sweden) scientists believe that city growth and projected increases in precipitation are set to worsen the current drainage problems, including the stability of the sewer system [12]. Results show, for example, that total daily solids per capita from the low income and ageing populations are almost twice that from high income or ethnic populations [13]. (Spence et al., 2016). For the stability of sewer system a combination of relatively simple technologies (e.g., source separation sewage systems, extended aeration activated sludge), significant reuse of assets (e.g., converting the aerated lagoons and facultative stabilization ponds into effluent storage basins), and a flexible treatment process configuration for a reliable, cost-effective, and efficient solution to address permits should be developed [14]. The advanced wastewater treatment facility (AWWTF) effectively and economically to reduce chemical and energy usage since before the treatment facility upgrades and since startup of those upgrades, while simultaneously removing more pollutants from the effluent and environment should be operated and maintained, too. In addition it need beneficially reuse biosolids through an on-site composting facility [15]. 
But what about Russia? Up to the very Urals the purification systems are heavily worn, while in Siberia they are a rarity altogether. As it frequently happens, the rigorousness of sanitary regulations is offset by the loose attitude to complying with them. According to the Russian Federation Ministry of Natural Resource report 'On condition and protection of the Russian Federation environment in 2007', 51.4 bnm $^{3}$ of main contaminants effluents were discharged with effluents in Russia. In 2008 it was 52.1 and in $2010-49.2$ [16].

Nearly $80 \%$ of the sewage water was discharged without treatment in 2010 in the Primorsk territory. In Perm more than 100 thous. $\mathrm{m}^{3}$ of sewage water have been discharged daily without treatment to the Kama River. In Kursk region 131 out of 139 STW have not provided required treatment. In Orel region $86 \%$ of untreated wastewater has entered water basins. In Moscow region only 42 (5\%) of 1356 STW have met requirements of maximum permissible discharge. The unreality of requirements helps the Federal Environmental, Engineering \& Nuclear Supervision Agency take high charges for discharge of contaminating impurities. It brings about the never-ending circle: it is impossible to prohibit operation of the sewage treatment works and at the same time radically improve them.

Earlier the wastewater in St Petersburg was also discharged without treatment directly into the Neva River and the Gulf of Finland. It is hard to believe but till the late 70s of the past century Petersburg did not have purification installations at all. As of 2001 operating in the city of St Petersburg were 125 public, 47 communal and 236 sectoral discharge facilities. As late as 2008, 375 direct discharges into the Neva and its tributaries were left untreated in the northern capital. The quality of water was catastrophic in the rivers of St. Petersburg and the Gulf of Finland. In 2006 the sea water of the near-shore area failed to comply with sanitary and chemical standards in $84.55 \%$ of the samples, and with microbiological standards in $93.78 \%$. According to Smirnova, the Baltic Sea has changed from oligotrophic with clean water to eutrophic, i.e. "blooming" water. The ecological situation worsened because the total standard index WCPI-10 (including the concentration of high-density metals, oil products, as well as sediment concentration and presence of anaerobic regions as the factors deteriorating the ecological state of the area) values were exceeded by 35-80 times. According to WCPI-10, a value of 55 meant the region of the Gulf of Finland near the Neva was an ecologically destructive region [17]. In suburban region of new builds concentrations of total nitrogen (TN) varied from 0.6 to $9.0 \mathrm{mg} / \mathrm{L}$, ammonium - from 0 to $6.8 \mathrm{mg} / \mathrm{L}$, total organic carbon (TOC) from 8.3 to $21.1 \mathrm{mg} / \mathrm{L}$. Increased concentrations of $\mathrm{TN}$ and ammonium at several sampling sites confirmed wastewater discharge from dwelling area. Polluted waters also showed higher values of electric conductivity and molar fractions for sodium and chloride ions, lower values of optical density (in range 230-420 nm) and TOC [18-19].

In 1986 Severniye purification installations were built west of the settlement of Olgino. At present, due to the construction of an extension of the main trunk sewer of the North (EMTSN), 98.4\% of sewage water (about $122 \mathrm{mln} . \mathrm{m}^{3}$ of sewage water per year) is being treated. When the main sewer project was completed, it was possible to close 76 direct discharges of sewage water and stop the discharge of untreated sewage water into the Neva. St Petersburg is one of the first Russian cities that have solved a problem of protecting the water basin from pollution [20-21]. That is why the purpose of the article is to present the design decisions used in the construction of the extended main trunk sewer of the North in St Petersburg. The authors show that it is necessary for source control techniques to be designed to counter increased discharge of water. It should provide the buildings with power saving technologies, hot water recirculation systems; and it should modernize the existing hot water supply facilities, and install low-cost highly efficient small heat 
exchangers instead of obsolete locally based boilers and just only of increasing the norms, coefficients and tariffs [22-23]. That is why a multi-objective sewer system optimization provides more rational and practical solutions to avoid sewer overflows, reduce risks to public health and to protect the environment from water pollution [24-25].

\section{Materials and methods}

The engineering methods and solutions proposed in EMTSN were the outcome of 30 years of activity. The immense experience gained from the construction and operation of underground structures, robust analysis of the operations of sewage pumping stations, and observations and experiments at operating sewerage trunk sewers were taken into account in the course of underground pipeline construction. The following were developed during this project:

- a new structure of the sewerage trunk sewer-underground pipeline with connections to wastewaters along the route,

- connecting assembly structures that allow for the motions of wastewaters and air entrained thereby,

- new well structures using composite materials,

- a new method for treating air being removed from the trunk sewer.

The project made it possible to complete the construction and launch operations of the trunk sewer that is reliable (though expensive!), ensures a complete discharge of the wastewaters into waste treatment facilities and makes the water basin of the North clean, which fully meets the goals of economic sustainability and safety conditions for the environment.

The main sewerage trunk collector: Pursuant to the general plan of sewage construction in St Petersburg all the principal trunk sewerages accepting the effluents were laid along water channels. Those, in compliance with the approved general discharge system, collect both communal-residential and industrial waste waters, as well as rain water. The main sewerage trunk sewer collector of the North runs along the right-hand bank of the Neva River (Figure 1).

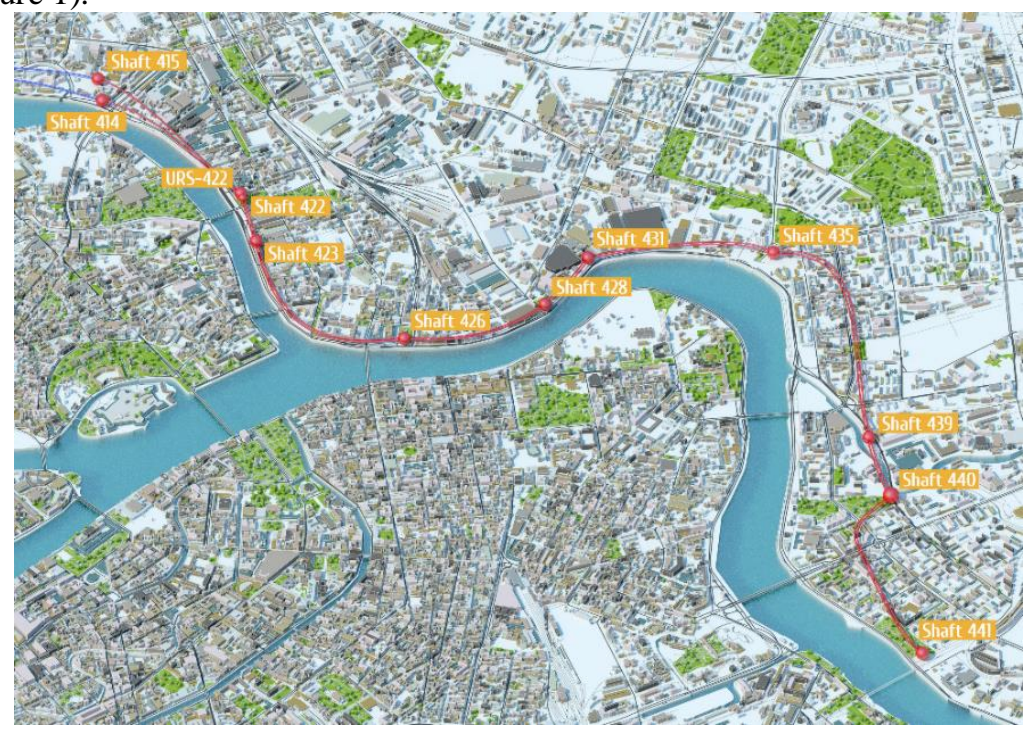

Fig. 1. Layout of EMTSN. 
The trunk sewer includes: two tunnels featuring length of $12.2 \mathrm{~km}$ and diameter of $4 \mathrm{~m}$ each laid as deep as 40-90 meters underground; 8 micro-tunnels of general length exceeding $7 \mathrm{~km}$; 64 wells; $5.2 \mathrm{~km}$ of street sewerage grid; runoffs regulation unit, a powerful pumping station located in the well featuring depth of $90 \mathrm{~m}$ and diameter of $24 \mathrm{~m}$. EMTSN is one of the most important, big complex and expensive projects of present-day Russia. Its design is aimed at overcoming problems related to weak soils. The trunk sewer run goes down to a sufficient depth and then rises to more shallow elevations as compared with the initial level. The application of such a technological solution has been substantiated by the geological peculiarities of St Petersburg. The trunk sewer construction began in 1986, continued up to 1995 and then, after a lengthy interval was resumed in 2001. The construction was fully completed in 2013. Investments from 2008 to 2013 amounted to about $0.8 \mathrm{bn}$ USD.

\section{Results}

The fact that the upper layers of soil (approximately down to $25 \mathrm{~m}$ ) are unstable were the conditions which predetermined that the sewerage construction project for the city on the Neva would be deep-laid. The Cambrian formation is below this, which resembles solid rock with respect to its properties. Therefore, installing wastewater transportation systems at such depths is quite reliable, though not cheap. Initially, there were several conditions that predetermined the structure design. As a result of calculations, experts noticed a significant decrease of flow velocities in dry weather down to $0.3-0.5 \mathrm{~m} / \mathrm{s}$ in the starting sections, and down to $0.5-0.7 \mathrm{~m} / \mathrm{s}$ at the trunk sewer outlet. It denoted the future silting of the trunk sewer run with the subsequent negative consequences of waste liquid transportation both in the underground pipeline itself and at its outlet. It should be noted that the intensive gas corrosion could have appeared in the starting area of the effective main trunk sewer with such a calculation. Moreover, it was necessary to have the flow velocity of $\mathrm{V} \geq 1.5 \mathrm{~m} / \mathrm{s}$ for transportation of the waste fluid with sand particles featuring dia. $\mathrm{d}=2.0 \mathrm{~mm}$. This condition determined two variants of underground pipeline structures at the stage of pre-design and design concepts.

Variant of the design concept: The underground pipeline with the runoff adjustment unit (URS-422) is to be arranged in the deepest point of the longitudinal underground pipeline profile, i. e. in the unit of the well No.422 (Figure 2).

The flow of liquid in the underground pipeline takes place in the pressure and gravity, free-flow and transition modes. In order to provide the liquid motion velocities to preclude silting of the underground pipeline run, the runoff adjustment unit (URS-422).

When consumption Q equals $0-8 \mathrm{~m}^{3} / \mathrm{s}$, the wastewaters are raised by pipes to the dump box elevation, and then they are supplied through a gravity tunnel to well No.415 at the end of the underground pipeline. A free-flow gravity motion is observed over the entire length of the underground pipeline from well No.441 to well No.422. When flows are Q>8 m3/s, URS-422 is switched off and the entire waste liquid flows through the up leg from well No.422 to well No.415 unit, while the pressure and gravity mode of the runoff is being established over the entire length of the underground pipeline. 


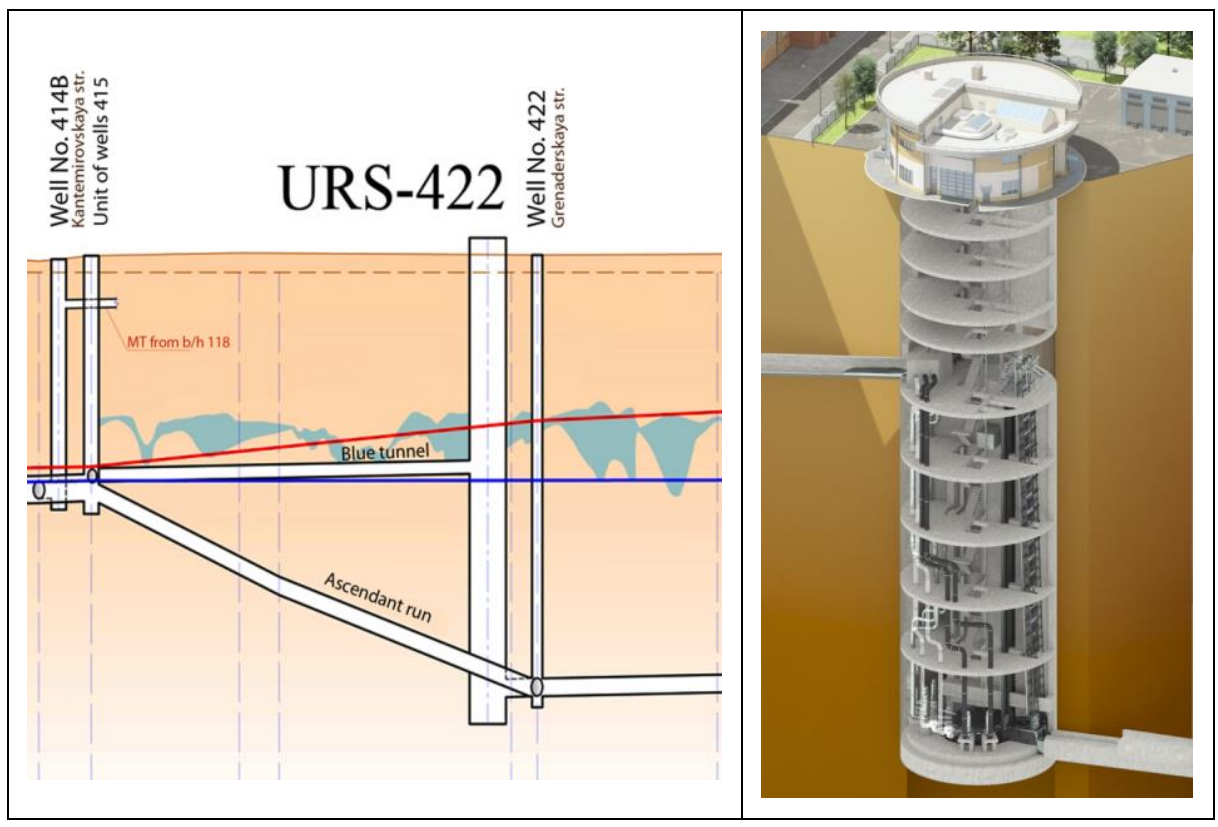

Fig. 2. Structure of URS-422 according to the 2nd variant of designing [26].

Current state of the problem: At the design stage of a new sewer or its renewal, the concentration of gases in the underroof space must be measured. Once the data has been calculated, decisions regarding sewer design, elevation differences, gradient and other parameters that ensure trouble-free operation can be made [27]. Thus, the underground pipelines correspond to underground excavations made by a mechanized shield with dia. of $4.03 \mathrm{~m}$ in the steady Proterozoic aggradations, which are secured by reinforced concrete blocks compressed into rock with an internal reinforced concrete jacket and a protective layer of polymer silicate Konusit KK-10 $(8-12 \mathrm{~mm})$ to protect against gas corrosion along the entire contour of the tunnel's inner surface. URS-422 is arranged in the space between the underground pipeline runs, in the deepest part of the tunnel trunk sewer in the well No.422 assembly. In the course of developing the design solution for URS-422, the following requirements were considered:

- well diameter accommodating URS-422 to be at least $20 \mathrm{~m}$;

- assembly to ensure a free-flow uniform mode of liquid motion in the runs of the underground pipelines at availability of flow up to $8 \mathrm{~m}^{3} / \mathrm{s}$ therein;

- to stay non-submerged when the piezometric surface of waste liquid rises, whether by pressure or by suction;

- to prevent ingress of rubbish and big objects into flow area of the pump impellers;

- to preclude any possibility of channel gas ingress from the underground pipeline run to the wet compartment;

- to ensure the operation of the pumping equipment in a wide range of time-variable wastewater flow;

- to ensure an alternate operation for every underground pipeline run. A disconnected underground pipeline run is to be available at this time for examination of its technical condition.

As a result, all of the EMTSN structures included several types of wells and structures with different purposes: 
- suction and junction wells of the head reach and concurrent reattachments;

- junction wells at the axis of underground pipeline;

- wells of head and lower reaches with shut-off shields;

- wells - distributors with shut-off shields;

- URS-422;

- air treatment process buildings;

- storage for pumping and production equipment;

- administration and amenity building with garage;

- central control room.

In order to clean the air removed from wells of the underground pipeline No.441 and No.415, the plasma-catalytic method is used by means of 'Plasqat-aero' installations. The air removed from distribution wells is cleaned by means of the ion exchange method.

\section{Discussion}

The standards for receiving wastewaters from the community $(350 \mathrm{~L} /$ day per person and more), advanced industry developments and storm water consumption were applied at the initial design stage of the trunk sewer when determining the trunk sewer tunnel diameter, resulting in a tunnel with an inner diameter of $3.2 \mathrm{~m}$ and outer tunnel diameter of $4.1 \mathrm{~m}$. Taking into account the pressure and gravity regimes, the expected liquid flow rate was assumed to be within a range of $0.7 \mathrm{~m} / \mathrm{s}$ to $1.5 \mathrm{~m} / \mathrm{s}$, ensuring the removal of contaminants from the trunk sewer run, and the chosen diameter was considered sufficient for transportation during dry weather and in case of rain.

A brief comment should be made here on the increased regulations for receipt of effluents from the population in Russia. According to the SNiP rules (construction standards and instructions) in the 2012 wording, the norms of daily discharge of communal effluents in the districts of urban development must be established depending on the degree of provision of amenities in these districts and with due regard to climatic, sanitary, hygienic and other local conditions (Table 1) (SNiP 2.04.03-85, release SP 31.13330.2012: 'Set of rules. Sewerage. Pipelines and wastewater treatment plants').

Table 1. Norms of effluent discharges in Russia for cities' existing individual buildings

\begin{tabular}{|l|c|c|c|}
\hline \multicolumn{1}{|c|}{ Name of effluent source } & $\begin{array}{c}\text { Unit of } \\
\text { measurement }\end{array}$ & $\begin{array}{c}\text { max. daily water } \\
\text { discharge, } \\
\text { L }\end{array}$ & $\begin{array}{c}\text { max. hourly } \\
\text { water discharge, } \\
\text { L }\end{array}$ \\
\hline Residential buildings: & 1 resident & 120 & 6.5 \\
\hline $\begin{array}{l}\text { with running water supply, sewage } \\
\text { without baths }\end{array}$ & & 225 & 10.5 \\
\hline $\begin{array}{l}\text { with running water supply, sewage } \\
\text { and baths with gas water heaters }\end{array}$ & 300 & 15.6 \\
\hline $\begin{array}{l}\text { with centralized hot water supply } \\
\text { with centralize hot water supply in } \\
\text { buildings higher than } 12 \text { storey }\end{array}$ & & 400 & 20 \\
\hline
\end{tabular}


The norm of effluent discharge is taken to be equal to that of water consumption. It is known that in the UK the norm of effluent discharge is 150-180-250 L/day. In St Petersburg, like generally in Russia, the standard norm for cold water consumption in houses without baths $\left(7.01 \mathrm{~m}^{3}\right.$ for a man per month) is overrated by a factor of two. Naturally, the effluent discharge is also overrated. For example, if the water consumption rate for 1 resident (in an apartment without a bath) is $120 \mathrm{~L}$ in a mean day, then in 30 days the water consumption will be $3.6 \mathrm{~m}^{3}$. If an apartment has no individual water meter, but instead of it a communal one is mounted, then the payment is made based on the standard norm.

According to officials, the growth of standard norms is one of the measures urging the population to install meters and counters. The resident pays for water based on the meter readings with standard amount of effluents in our case being $7.01 \mathrm{~m}^{3}$. However, Gorvodokanal (City's Water Supply and Discharge Department), does not make any amendments for the consumer though the actual water consumption has dropped. So it happens that the consumer's actual rates for water supply and discharge remain overestimated. In addition, in estimations the factor "mean daily water discharge" is often replaced with another, "water discharge in days of the highest water consumption". The company opts for the higher standard, obviously believing that the resident are busy all day long without a break washing up and laundering. So, even though the specific daily water discharge is allowed to be changed by $10-20 \%$ depending on climatic and other local conditions and degree of amenities provided, in actual fact a managing company is getting super-profits without any efforts to adjust in the buildings the hot water recirculation systems, modernize the existing hot water supply facilities, and to install low-cost highly efficient small heat exchangers instead of obsolete locally based boilers.

On the other hand, the suppliers say that the payment covers only $70 \%$ of their services, which is why the rates must be continuously increased. In addition, recently settlements have been introduced for consumption of communal hot water (the standard norm is $1.5 \mathrm{~m}^{3}$ per man). This figure is calculated by the Regional Energy Supply Commission based on the Government's decree. Since 1 January 2015 the payments for water discharge will be made based on the increased index (1.5). The City's Water Supply and Discharge Department, managing companies and other participants of the communal sector assure a permanent profit for themselves by not reducing the price of services, not introducing power saving technologies, but just only increasing the norms, coefficients and tariffs.

Resulting from the change of the socio-economic system in the state and due to coming up market relations in 1993 normative standards of water use were reconsidered both for the community and for the industry (Table 2 ).

Table 2. Water discharge pattern for the Russian population

\begin{tabular}{|c|c|c|c|}
\hline \multirow{2}{*}{ Facilities provided with sewage } & \multicolumn{3}{|c|}{$\begin{array}{r}\text { Specific mean daily (yearly) water discharge per one } \\
\text { resident in built-up area (L/day) }\end{array}$} \\
\cline { 2 - 4 } & Before 1990 & Before 2000 & 2019 \\
\hline Towns & 500 & 550 & 350 \\
\hline Villages & 125 & 150 & 160 \\
\hline
\end{tabular}

As for the development of sewerage in Russia, the main tasks for the nearest years will be the installation of assemblies for cleaning from biogenous contamination and 
decontamination of the treated wastes. According to Mishukov and Smirnova (2017), the best solution for large treatment facilities is the use of a reliable method for the biological removal of phosphorus from incoming wastewater, and separate sediment dewatering combined with reagent-assisted treatment of local flows, whereas for small and medium stations the optimum is a combined purification of the entire incoming drain flow [28]. However, in 2017 the cost of works is too high, in order to make these plans come true. Taking into account the inevitable growth of prices for utilities one can expect building of the methane digesters in combination with installations for production of heat and electric power from biogas. The economic effect, technical practicality and social impact of the construction of the deep level sewers are confirmed as a reliable though very expensive structure [29].

\section{Conclusions}

1. The authors conclude that the new pit structures using composite materials made it possible to complete construction of the trunk sewer on schedule and by means of it to move to purification works practically all of the city's effluents $(98,4 \%)$, which realize the goal of sustainable economic development. This made it possible to complete the construction and launch operations of the trunk sewer of the North, a structure that is reliable (though very expensive!), ensures a complete discharge of the wastewaters into the waste treatment facilities and makes the water basin of the North clean, thereby fully accomplishing the goals of economic sustainability and safety conditions for the environment.

2. Following the example of St Petersburg the big industrial cities will build plants for burning sediments. The burial ground disposal and disposal at the landfills will remain in the middle and small communities. The economic effect, technical practicality and social impact of the construction of the deep level sewers are confirmed as a reliable though very expensive (!) structure. It is necessary that source control techniques be designed to counter increased discharge of water. Buildings should be provided with power saving technologies, hot water recirculation systems. In addition, it is necessary to modernize the existing hot water supply facilities, and to install low-cost highly efficient small heat exchangers - instead of obsolete locally based boilers - rather than just increasing the norms, coefficients and tariffs.

3. On the other hand, the problem of finding a sustainable development (climate model projections, the climate change impact analysis of design storms, peak flows and flooding scenario, etc.) is connected with the strategies and techniques of a sustainable urban drainage system (green roofs, permeable pavements, rainwater harvesting, infiltration trenches, infiltration basins, filter strips into landscaped areas, filter drains (or French drains), surface water swales, etc., to counter increased discharge of water).

\section{References}

1. P.E. Myerscough \& C.J. Digman, Proceeding of the 11th International Conference on Urban Drainage (11 ICUD 2008), International Association for Hydraulic Research, International Water Association, IAHR/IWA, (Reston, VA: Elsevier, 2008).

2. M. Kavanagh, Financial Times (November 3, 2011). http://www.ft.com/intl/cms/s/0/16c68fba-0640-11e1-a07900144feabdc0.html\#axzz30Mbbhf7IE 
3. M. Kavanagh, Financial Times (December 2, 2012). http://www.ft.com/intl/cms/s/0/c50da1e6-3c9d-11e2-a6b200144feabdc0.html\#axzz30Mbbhf7I

4. J.F. Brotchie, J.W. Dickey, R. Sharpe, TOPAZ - General Planning Technique and Its Applications at the Regional, Urban, and Facility Planning Levels. Ser.: Lecture Notes in Economics and Mathematical Systems (LNE), vol. 180, 110-133 (Springer. Berlin; Heidelberg; GmbH, 1980).

5. G.A. Earle, R.P. Farrell, Estimating sewer costs: a mathematical model (2012). https://www.wateronline.com/doc/estimating-sewer-costs-a-mathematical-model-0001

6. R.P. Farrell, J. of the New Engl. Water Pol. Control Assoc. 26(1), 38-47 (1992).

7. G.A. Earle \& R.P. Farrell, Low-pressure sewer systems: economic advantages from construction through operation and maintenance (2016). https://www.wateronline.com/doc/low-pressure-sewer-systems-economic-advantage0001.

8. S. Shukla \& V. Tare, Handbook of Environmental Materials Management, 1-32 (Springer / Cham, New York, 2019).

9. V. Tare \& P. Bose, J. of Environ. Sc. and Eng. 56, 137-146 (2014).

10. V. Tare \& P. Bose, Compendium of sewage treatment technologies (National River Conservation Directorate, Ministry of Environment and Forests, New Delhi, 2009). http://nmcg.nic.in/writereaddata/fileupload/15_Technologies\%20Involved.pdf

11. P.H. Dodane, M. Mbéguéré, O. Sow, L. Strande, Environ. Sc. \& Tech. 46(7), 37053711 (2012). https://doi.org/10.1021/es2045234

12. A. Semadeni-Davies, C. Hernebring, G. Svensson, L-G. Gustafsson, J. of Hydrol. 350(1-2), 100-113 (2008). https://doi.org/10.1016/j.jhydrol.2007.05.028

13. K.J. Spence, C.J. Digman, D. Balmforth, J. Houldsworth, A. Saul, J. Meadowcroft, Urb. Water J. 13(8), 773-789 (2016). https://doi.org/10.1080/1573062X.2015.1025081

14. A-K. Skambraks, H. Kjerstadius, M. Meier, E. Davidsson, M. Wuttke, T. Giese, Sustain. Cities Soc. 28, 287-296 (2017). https://doi.org/10.1016/j.scs.2016.09.013

15. L. Shields, A. Brousseau, J. of New Engl. Water Environ. Assoc. 51(3), 26-34 (2017).

16. K.E. Laykam, Federalnaya Sluzhba Gosudarstvennoy Statistiki (Rosstat): Okhrana Okruzhayushchey Sredy v Rossii: Statisticheskiy Sbornik [Environment protection in Russia: Statistics digest] (Rosstat, Moscow, 2012).

17.E. Smirnova \& M. Alexeev, J. of Environ. Eng. and Sc. 11(3), 67-78 (2016). https://doi.org/10.1680/jenes.14.00012

18. E. Smirnova \& M. Alexeev, Environ. Sc. and Poll. Res., 24(14), 12835-12846 (2017). https://doi.org/10.1007/s11356-017-8857-0

19. K.V. Ilina, N.M. Gavrilova, Y.A. Bondarenko, M.Y. Andrianova, A.N. Chusov, Magaz. of Civ. Eng. 8(76), 240-254 (2017). https://doi.org/10.18720/MCE.76.21

20. N. Medvedeva, Y. Polyak, H. Kankaanpaa, T. Zaytseva, Marin. Environ. Res. 68, 7181 (2009). https://doi.org/10.1016/j.marenvres.2009.04.007

21. V.V. Dzyubo, L.I. Alferova, V.M. Vasilyev, Water and Ecol.: Probl. and Solut. 2(74), 10-16 (2018). https://doi.org/10.23968/2305-3488.2018.20.2.10-16

22. D. Grasmanis, D.O. Sovetnikov, D.V. Baranova, Magaz. of Civ. Eng. 8(76), 140-155 (2017). https://doi.org/10.18720/MCE.76.13. 
23. F. Kuznik, K. Johannes, D. David, Advances in Thermal Energy Storage Systems: Methods and Applications. Ser.: Woodhead publishing series in energy, vol. 66, 325353 (Woodhead Publishing / Elsevier Science \& Technology, Cambridge, 2017). https://doi.org/10.1533/9781782420965.2.325

24.F. Qiao, Y. Wanyan \& Q. Li, Civ. Eng. Res. J. 3(4), Article 555616 (2018). https://doi.org/10.19080/CERJ.2018.03.555616

25. Z. Henderson \& D. Hall, J. of New Engl. Water Environ. Assoc. 51(3), 36-41 (2017).

26. V. Vasilyev, F. Vasilyev, Proceed. of Inst. of Civ. Eng.: Waste and Resour. Manag. 169(1), 42-51 (2016). https://doi.org/10.1680/jwarm.14.00022

27. G. Tchobanoglous, H. Stensel, R. Tsuchihashi, F. Burton, M. Abu-Orf, G. Bowden, Wastewater Engineering: Treatment and Resource Recovery (McGraw-Hill, New York, 2014).

28. B. Mishukov \& E. Smirnova, Proceed. of the Inst. of Civ. Eng.: Water Manag. 170(4), 184-197 (2017). https://doi.org/10.1680/jwama.14.00160.

29. V. Vasilyev, F. Vasilyev, Contemporary Problems of Architecture and Construction 7th International Conference, 413-416 (The factory S.r.1., Roma, 2015). 